Thorax (1969), 24, 543.

\title{
Surgical management of traumatic cardiac fistulae
}

\author{
MICHAELA. ROGERS ${ }^{1}$, ELLIOT CHESLER, AND \\ LOUIS DU PLESSIS \\ From the Cardio-thoracic Surgical Unit, Baragwanath Hospital, University of the Witwatersrand, \\ Johannesburg
}

Seven cases of traumatic intracardiac lesions following penetrating stab wounds of the heart are presented. The surgical management and complications encountered in these cases are discussed.

Seventy-one years ago Professor L. Rehn successfully repaired a wound in the right ventricle of Wilhelm Justis, who had been stabbed in the chest (Rehn, 1897). Since then there have been many reports of successful management of patients with penetrating stab wounds of the heart and few have had residual structural damage. As recently as 1965 Summerall, Lee, and Boone, in a report of two cases of traumatic cardiac fistula, reviewed the literature and could find only 12 cases of intracardiac shunt due to penetrating wounds of the heart.

The purpose of this paper is to present seven cases of traumatic intracardiac lesions encountered during the past four years in African men at Baragwanath Hospital. The management and results are summarized in the Table.

\section{CASE REPORTS}

CASE 1 A 29-year-old African man was stabbed in the chest just above the lefit nipple. Pericardial aspiration failed to relieve the clinical features of cardiac tamponade. At thoracotomy clot was evacuated from the pericardial sac and a wound in the anterior wall of the right ventricle was sutured. Forty-eight hours later a loud pansystolic murmur was heard over the whole praecordium; cardiac decompensation ensued and this responded to digitalis therapy.

One month after injury cardiac catheterization revealed a left-to-right shunt at ventricular level. The mean pulmonary arterial pressure was $25 \mathrm{~mm}$. Hg. Left ventricular cineangiography demonstrated a defect in the muscular interventricular septum. The aortic and mitral valves were normal. Eight weeks after injury, with cardiopulmonary bypass and through a right ventriculotomy, a circular defect, $1.5 \mathrm{~cm}$. in diameter and with a fibrotic margin, was found low in the muscular interventricular septum; the defect was closed with a Teflon patch anchored with interrupted

1Present. address: Cardio-thoracic Unit, Wentworth Hospital, Durban, Natal. sutures. Recovery was uneventful and the patient was asymptomatic two years after surgery.

CASE 2 An African man, aged 29 years, was stabbed through the fifth left intercostal space at the sternal border. Initial examination revealed a small haemopneumothorax, and 48 hours after injury the patient was discharged from hospital. Four months later he was referred to the Cardio-thoracic Unit because of congestive cardiac failure, and a continuous murmur was heard over the whole of the praecordium, loudest directly over the stab wound.

Radiographically both right and left ventricles were enlarged and the lung fields were plethoric. At cardiac catheterization there was evidence of a left-to-right shunt at ventricular level. The mean pulmonary arterial pressure was $26 \mathrm{~mm}$. Hg. Aortography demonstrated a fistula between the base of the aorta and the outflow tract of the right ventricle. In addition, there was some aortic regurgitation. A left ventriculogram showed an intact interventricular septum.

The fistula was repaired using cardio-pulmonary by-pass. A defect, $1 \mathrm{~cm}$. in diameter communicating with the aorta, was found in the posterior wall of the right ventricular outflow tract. Closure of the defect was with interrupted sutures bolstered with Teflon. A slit in the non-coronary aortic cusp was repaired by direct suture. Minimal residual aortic incompetence did not jeopardize recovery.

CASE 3 A 42-year-old man was stabbed with a screwdriver in the third left intercostal space at the sternal border. He was observed in an outlying hospital for 24 hours and then discharged, apparently well. Thereafter he developed dyspnoea on effont, which became slowly but progressively more severe. One year after being stabbed he was referred to the Cardio-thoracic Unit, where he was found to be in congestive cardiac failure. A systolic thrill was palpable directly over the stab wound and a grade 5/6 pansystolic murmur, loudest in the fourth left intercostal space, was heard over the whole praecordium. The pulmonary second sound was accentuated and paradoxically split. The electrocardiogram showed lefit bundle-branch block. Radiographically there was pulmonary plethora, ven- 
T A B L E

SUMMARY OF PATIENTS WITH TRAUMATIC INTRACARDIAC FISTULAE

\begin{tabular}{|c|c|c|c|c|c|c|c|c|}
\hline \multirow{2}{*}{ Case } & \multirow{2}{*}{ Age } & \multirow{2}{*}{ Sex } & \multirow{2}{*}{$\begin{array}{l}\text { Method } \\
\text { of } \\
\text { Injury }\end{array}$} & \multirow{2}{*}{$\begin{array}{l}\text { Anatomical } \\
\text { Diagnosis }\end{array}$} & \multirow{2}{*}{ Complications } & \multicolumn{2}{|c|}{ Management of Injury } & \multirow{2}{*}{ Results } \\
\hline & & & & & & Primary & Definitive & \\
\hline 1 & 29 & $\mathbf{M}$ & Stab wound & V.S.D. & - & Thoracotomy & Patch & Asymptomatic \\
\hline 2 & 29 & $\mathbf{M}$ & Stab wound & $\begin{array}{l}\text { Aorto-R.V. } \\
\text { fistula + A.I. }\end{array}$ & - & None & $\begin{array}{l}\text { repair } \\
\text { Suture }\end{array}$ & Residual A.I. \\
\hline 3 & 42 & $\mathbf{M}$ & Stab wound & V.S.D. & - & None & $\begin{array}{l}\text { Patch } \\
\text { repair }\end{array}$ & Total heart blo \\
\hline 4 & 24 & $\mathbf{M}$ & Stab wound & $\begin{array}{c}\text { Aorto-R.V. } \\
\text { fistula }\end{array}$ & - & Thoracotomy & None & - \\
\hline 5 & 40 & $\mathbf{M}$ & Stab wound & $\begin{array}{l}\text { Aorto-R.V. } \\
\text { fistula }\end{array}$ & $\begin{array}{l}\text { Cerebral } \\
\text { embolus }\end{array}$ & Thoracotomy & None & - \\
\hline 6 & 29 & $\mathbf{M}$ & Stab wound & V.S.D. & - & None & $\begin{array}{l}\text { Patch } \\
\text { repair }\end{array}$ & \\
\hline 7 & 23 & $\mathbf{M}$ & Stab wound & $\begin{array}{l}\text { Aorto-pulm. } \\
\text { artery fistula }+ \\
\text { A.I. }\end{array}$ & $\begin{array}{l}\text { Cerebral } \\
\text { embolus }\end{array}$ & None & Suture & Asymptomatic \\
\hline
\end{tabular}

tricular enlargement, and some prominence of the pulmonary artery. Cardiac catheterization demonstrated a left-to-right shunt at ventricular level. The mean pulmonary arterial pressure was $27 \mathrm{~mm}$. $\mathrm{Hg}$. A left ventricular cineangiogram demonstrated a ventricular septal defect; the aortic and mitral valves were normal.

Repair of the defect was undertaken with cardiopulmonary bypass. The interventricular septum was exposed through a right ventriculotomy; a large defect with fibrotic margins was found high in the interventricular septum and was closed with a Teflon patch anchored with interrupted sutures.

An electrocardiogram made 24 hours after surgery showed, in addition to the left bundle-branch block, a prolonged $\mathbf{P}-\mathbf{R}$ interval. Forty-eight hours after surgery the electrocardiogram showed complete $A-V$ disassociation with a ventricular rate of $75 / \mathrm{min}$; this progressed to complete A-V block.

The patient declined to have a cardiac pacemaker inserted and was discharged, since his capacity for exertion was satisfactory despite a pulse rate consistently below $50 /$ minute.

CASE 4 An African man of 24 years was stabbed in the fourth intercostal space just to the right of the sternum. The blood pressure was $50 \mathrm{~mm}$. $\mathrm{Hg}$ on admission and there were signs of cardiac tamponade. A continuous murmur was heard along the left sternal border.

Pericardiocentesis failed to relieve the tamponade. At thoracotomy the pericardium was seen to be distended with liquid blood and clot; a stab wound, $3 \mathrm{~cm}$. in length, in the anterior wall of the right ventricular outflow tract was repaired. Forty-eight hours later he was found to be in congestive cardiac failure ; there was a continuous murmur over the whole of the praecordium, loudest in the second left intercostal space.

Radiographically the lungs were moderately congested and there was left ventricular enlargement. Response to treatment with digoxin and diuretics was satisfactory.
Cardiac catheterization revealed a left-to-rig shunt at ventricular level. The mean pulmonaf arterial pressure was $16 \mathrm{~mm}$. Hg. A left ventriculo gram showed an intact interventricular septum wit out mitral incompetence. An aortogram demonstrated a fistula between the root of the aorta and the outflog of the right ventricle; the aortic valve was competent.

The patient refused surgery and he was not seen again.

CASE 5 A 40-year-old African man was admitted hospital in a state of circulatory collapse following a stab in the chest. Profound hypotension persisted despite blood transfusion and aspiration of the per⿳亠丷厂犬 cardium, and thoracotomy was therefore undertake as an emergency. Approximately $200 \mathrm{ml}$. of blood was found in the pericardium and a small wound the wall of the right ventricular outflow tract was sutured. Post-operatively the patient was noted have a dominant expressive aphasia and a right hemiparesis.

Six weeks later he was in congestive cardiac failure A continuous murmur, loudest in the third left interspace, was heard over the whole of the praecordium? the first and second heart sounds were normal. Radio graphically there was some increase in pulmonat vascular markings.

At cardiac catheterization two months after inju the mean pulmonary arterial pressure was shown to be $20 \mathrm{~mm}$. Hg. A catheter introduced via the righo brachial artery passed directly from the root of the aorta into the right ventricle (Figure). Aortograph demonstrated the fistula: the aortic valve was conse petent and the interventricular septum intact.

The patient refused further treatment.

CASE 6 An African man of 29 years was referred the Cardio-thoracic Unit five months after bein stabbed in the chest. Initial management had been b observation. There was a one-inch scar over the miథ sternum. The heart was not enlarged clinically; 8 systolic thrill was palpable at the site of the stao wound and a grade $5 / 6$ pansystolic murmur, loudeg 


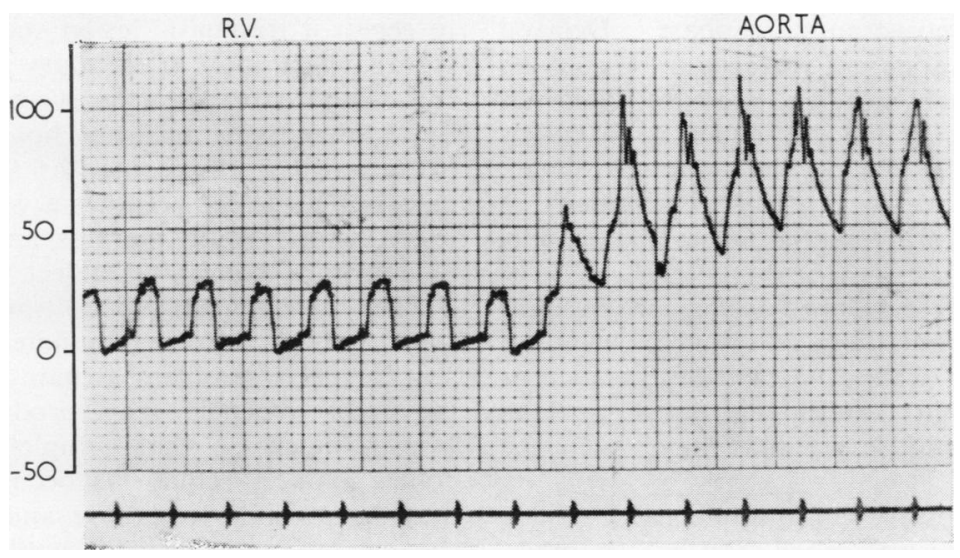

FIGURE. Case 5. Withdrawal pressure tracing from right ventricle to aorta, the catheter passing along the tract of the aortico-right ventricular fistula.

in the fourth left interspace, was heard over the whole praecordium. A mid-diastolic murmur was present in the mitral area. The electrocardiogram showed sinus rhythm and right bundle-branch block. Radiographically there was enlargement of the left ventricle, with a prominent pulmonary artery segment and plsthoric lung fields. Cardiac catheterization demonstrated a left-to-right shunt at ventricular level and cineangiography confirmed the presence of a ventricular septal defect. The mean pulmonary arterial pressure was $17 \mathrm{~mm}$. Hg.

Surgical repair of this lesion was performed six months after the injury. After cardio-pulmonary bypass had been established the interventricular septum was exposed through a right ventriculotomy and a defect in the mid interventricular septum was closed with a Teflon patch, anchored with interrupted sutures. The post-operative course was uneventful and the patient is well.

CASE 7 An African man of 23 years was admitted to an outlying hospital two days after being stabbed in the left side of the chest. He was in congestive cardiac failure and had a paralysed right arm and a dominant expressive aphasia. Before injury he had been well.

Four months later he was referred to the Baragwanath Cardio-thoracic Unit. There was residual weakness of the right arm and some residual aphasia. The clinical features were those of congestive cardiac failure with a grade $4 / 6$ pansystolic murmur and a short mid-diastolic murmur at the apex of the heart; a continuous murmur, loudest in the third left intercostal space, was present along the left sternal border ; the pulmonary second sound was accentuated.

Radiographically the left ventricle and pulmonary artery were enlarged and the lung fields were moderately plethoric. The electrocardiogram showed a mean frontal plane axis of $+60^{\circ}$ with evidence of left ventricular and left atrial enlargement. Cardiac catheterization revealed a left-to-right shunt at pulmonary artery level. The mean pulmonary arterial pressure was $50 \mathrm{~mm}$. $\mathrm{Hg}$. Cineangiography (with injections into both the left ventricle and aorta) demonstrated a fistula between the base of the aorta and the main pulmonary artery with some aortic incompetence.

Repair of the fistula was performed using cardiopulmonary bypass. The left coronary sinus communicated through a large opening, where the aortic ring had been detached, with both the left ventricle and the pulmonary artery. The defect was closed by direct suture.

The patient made an uninterrupted recovery and no murmurs were heard at the time of discharge.

\section{DISCUSSION}

Some 1,500 patients with stab wounds of the chest are treated at Baragwanath Hospital each year. Of these, $2-3 \%$ have evidence of cardiac damage. The signs vary from the electrocardiographic changes of pericarditis to cardiac tamponade. In the majority of cases the stab wound involves either the right or left ventricle. Where the atria or aorta are involved, survival is rarely long enough for the patient to reach the casualty department. The cutaneous entrance wound may be small and need not be directly related to the heart; the possibility of involvement of the heart must always be borne in mind when treating a stab wound of the chest.

There may not be detectable evidence of structural damage of the heart immediately following a penetrating stab wound. For example, in cases 2,3 , and 5 a cardiac murmur was not detectable 
during the early post-traumatic phase. Delayed appearance or an apparent increase in size of the fistula between high and low pressure chambers of the heart may be the consequence of earlier obstruction of the fistula by clot or fibrin. Frequent surveillance of cases of stab wounds of the chest is therefore essential if residual shunts are to be detected.

Cases 5 and 7 developed signs of cerebral damage in close relation to injury; thrombus detached from the wall of a cardiac chamber or air or other foreign material entrained into the heart at the time of injury may have been the cause.

Since lesions may be multiple with valve damage and fistulae into more than one chamber, complete investigation by cardiac catheterization and angiography are essential if successful repair is to be performed.

Repair of a traumatic intracardiac defect is not indicated in the early post-traumatic period unless cardiac decompensation fails to respond to medical management. Small ventricular septal defects may close spontaneously, and we have observed cases in which the clinical features of a small traumatic intracardiac shunt have disappeared within a few weeks of injury. An attempt to repair a traumatic lesion such as a ventriculag septal defect soon after injury may be unsuccess ful, as the damaged area is not well defined an the friable tissue will not hold sutures securelfo Within two or three months a traumatic ventris cular septal defect becomes a well-defined circula $\overrightarrow{5}$ lesion with fibrotic margins and is indistinguishable from a congenital defect.

The management of a traumatic ventricula: septal defect with a left bundle-branch block pre sents a special problem. Repair of a defect through the right ventricle may produce right bundler branch block, so that complete heart block be comes a likely sequel (as occurred in case 3 ). may be possible to expose and repair the defece through the aortic valve, unless the defect i $\vec{b}$ the septum is low, and in these circumstances the surgeon must be prepared to manage idioventro cular rhythm by pacing.

We wish to thank Dr. W. H. F. Kenny, Medical Superintendent of Baragwanath Hospital, for permi $\overrightarrow{80}$ sion to publish.

\section{REFERENCES}

Rehn, L. (1897). Ueber Penetrirende Herzwunden und Herznahe Arch. clin. Chir., 55, 315.

Summerall, C. P. 3rd., Lee, W. H. jr., and Boone, J. A. (1965). Inträ cardiac shunts after penetrating wounds of the heart. New Eng J. Med., 272, 240 . 